\title{
ON THE SEASONAL VARIATION IN THE IODINE CONTENT OF THE THYROID GLAND.
}

\author{
Frederic Fenger \\ Research Laboratory in Organotherapeutics, Armour \& Company, \\ Chicago, Ill.
}

In previous communications on this subject it was shown that a marked seasonal variation exists in the iodine content of the thyroid gland of cattle, hogs and sheep. There is in general from two to three times as much iodine present in the glands in the months between June and November as in the months between December and May. (1) A more or less regular seasonal change in the size of the fresh gland exists in the case of cattle and sheep, but not in hogs. A consideration of the several causes for the fluctuations leads to the conclusion that the temperature is perhaps the most important of all. (2)

These investigations were conducted from September, 1911, to December, 1913, during which time samples of fresh glands were collected twice a week and stored at freezing temperature. The glands were trimmed, prepared and analyzed twice a week. The bi-monthly samples represented about ten pounds of fresh glands.

During the past four years, 1914-1917, data have been accumulated on more than one hundred lots of desiccated thyroids from cattle, hogs and sheep which furnish the raw material for medicinal thyroid preparations. The samples were supplied by the factory and analyzed in this laboratory for control purposes. 
Fach of these lots represent many thousand glands and the collection time covered periods of several weeks. The animals furnishing the raw material came from all parts of the United States, with the exception of a few of the Eastern and Southeastern States. It is evident, therefore, that such factors as locality, feed, water, and particularly the considerable individual variation which is known to exist, have been satisfactorily eliminated. The fundamental causes for the fluctuations in the iodine content of the thyroid gland consequently must be temperature and weather conditions.

In the tabulation below are given the maximum and minimum iodine content of the thyroid glands collected during the two periods mentioned above and the yearly averages for the entire six years. All figures are calculated to a dry fat-free basis.

Percent of Iodine in dessicated fat-free glands

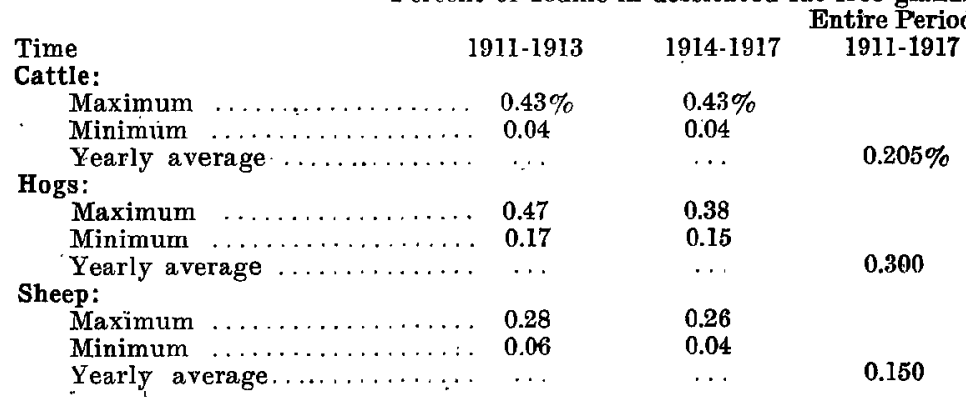

It will be seen that the figures obtained during the last four years are almost identical with the earlier findings, as far as cattle and sheep are concerned. In case of the hog, the differences are more marked. This is in all probability due to the decreased number of hogs slaughtered during hot weather and the extended collection time.

The average iodine content of the hog thyroid, 
taken year by year, is considerably above that of cattle and sheep. This may be of some significance, since the former is an omnivorous animal, while the latter are strictly herbivorous.

The seasonal variation in the size of the thyroid gland of cattle and sheep has been referred to above. of these, the beef gland particularly is influenced by cold temperatures. It has been noticed year after year that the onset of severe cold weather is followed in a week or two by a noticeable enlargement of the cattle glands and consequent lowering of iodine content. This enlargment is less prominent or occurs later in mild winters than in severe ones. The glands of sheep are also quite sensitive to temperature changes, but not to the same degree as those of cattle.

Fluctuations in the yearly average iodine content of the thyroid gland also exists. These are naturally small and vary but a few hundredths of one per cent from year to year. They are undoubtedly due to weather conditions generally.

Where due allowances are made for climatic fluctuations and the differences in the time periods of collection, the last four years' results, when plotted out on paper, follow closely the curves published in previous reports.

\section{SUUMMARY}

Additional evidence has been furnished to show that a distinct seasonal variation exists in the iodine content of the thyroid gland from cattle, hogs and sheep. The temperature factor is the most important of all in producing these fluctuations.

\section{BIBLIOGRAPHY}

1. Seidell and Fenger. J. Biol. Chem., 1913, 13, 517.

2. Seidell and Fenger. Bull. No. 96, Hygienic Laboratory U. S. P. H. S., 1914, p. 67. 